\title{
The Demystification of Autoscopic Phenomena: Experimental Propositions
}

\author{
Christine M ohr, PhD* and O laf Blanke, MD, PhD
}

\begin{abstract}
Address
*D epartment of Experimental Psychology, U niversity of Bristol, 8 W oodland Road, Bristol, BS8 1TN , U nited Kingdom.

E-mail: christine.mohr@ bristol.ac.uk
\end{abstract}

Current Psychiatry Reports 2005, 7:189-195

Current Science Inc. ISSN 1523-3812

Copyright $\odot 2005$ by Current Science Inc.

A utoscopic phenomena (AP) are rare, illusory visual experiences during which the subject has the impression of seeing a second own body in extrapersonal space. AP consist of out-of-body experience, autoscopic hallucination, and heautoscopy. Recent neurologic reports support the role of multisensory integration deficits of bodyrelated information and vestibular dysfunctions in AP at the temporo-parietal junction. A caveat to test the underlying neurologic and co gnitive mechanisms of AP has been their rare and spontaneous occurrence. Recent evidence linked AP to mental own-body imagery engaging brain mechanisms at the temporo-parietal junction. These recent observations open a new avenue for testing AP-related co gnitive mechanisms in selected clinical and normal populations. We review evidence on several clinical syndromes (psychosis, depression, anxiety, depersonalization, body dysmorphic disorder), suggesting that some of these syndromes may relate to AP-proneness, thereby leading to testable propositions for future research on body and self processing in addition to AP.

\section{Introduction}

The self as an entity distinct from other human conspecifics may be described as an enduring and spatial entity (the feeling that we are the same person across time and space) to which certain mental events and actions are ascribed (the feeling of agency; being author of one's own thoughts and actions) and which is distinct from the environment [1]. The many concepts of the self have been influenced by theology, philosophy, and psychology [2-4,] but also by clinical observations from the fields of neurology and psychiatry $[1,5-7,8 \cdot \bullet]$. One group of clinical phenomena may be especially fruitful in this respect: autoscopic phenomena (AP). During AP, the individual sees a second own body in extrapersonal space, associated to varying degrees by a separation of the self from the body. AP challenge our notions about the experienced unity of self and body, localization of the self, and agency $[2,4,9 \bullet]$. This review describes recent scientific approaches to AP and body and self processing and makes testable predications for future research.

Autoscopic phenomena generally are classified among disorders of somatognosia and include various shortlasting (usually), illusory experiences about the location and position of one's body or body parts [10-12]. They generally occur in patients with posterior brain damage and are characterized by illusions that only affect a certain body part (body-part illusions) or affect the entire body (body illusions or AP) $[8 \cdot \bullet, 10,12]$. Recently, phenomenologic, functional, and anatomic mechanisms of AP and their importance for mechanisms of self processing have been reported $[5,8 \bullet \bullet, 13,14 \bullet \cdot]$. It has been speculated that these phenomenologic characteristics point to similar and distinct neurocognitive mechanisms in the three main forms of AP $[5,8 \bullet \bullet]$.

\section{Definition of the Three Main \\ Autoscopic Phenomena}

During an out-of-body experience (OBE), people seem to be awake and feel that their "self," or center of awareness, is located outside of the physical body and is somewhat el evated (disembodiment). It is from this el evated extracorporeal location that the subjects experience seeing their body and the world (for overview see $[8 \bullet, 13,14 \bullet \bullet, 15,16]$ ). The subjects' reported perceptions are organized in such a way as to be consistent with this el evated visuo-spatial perspective. Therefore, an OBE can be defined as the presence of disembodiment, distanced and elevated visuospatial perspective, and autoscopy.

During an autoscopic hallucination $(\mathrm{AH})$, a person experiences seeing his double in extracorporeal space without leaving his own body (no disembodiment). As compared with OBEs, individuals with $\mathrm{AH}$ experience seeing the world from their habitual visuo-spatial perspective and experience their "self," or center of awareness, inside their physical bodies.

Lastly, during a heautoscopy (HAS), theindividual al so has the experience of seeing a double of himself in extracorporeal space However, it is difficult for the subject to decide whether he is disembodied and whether the self is localized within the physical body or in the autoscopic body [8・•]. In addition, the subjects often report seeing 
the world simultaneously or in an al ternating fashion from the physical body and the double's body. For additional details see Brugger [14••] and Blankeet al. [8••].

\section{Neurology Etiologic mechanisms}

Autoscopic phenomena have been reported in various diseases of the central nervous system and may be attributable to generalized disease (meningitis, encephal itis, intoxications, generalized epilepsies) or focal disease (focal epilepsy, traumatic brain damage, migraine, vascular brain damage, neoplasia) $[5,8 \cdot \bullet, 13,17]$. In regard to focal brain damage, these studies primarily implicated posterior brain regions, including the temporal, parietal, or occipital lobes $[5,13]$. More recently, Blanke and Arzy [18], Blanke et al. $[8 \cdot \bullet, 19]$ and Maillard et al. [20] suggested that AP may be related primarily to damage at the temporo-parietal junction (TPJ) of either hemisphere.

\section{Functional mechanisms}

Many different functional mechanisms have been proposed in the study of AP, including visual (hallucinatory) mechanisms, proprioceptive and/or kinaesthetic mechanisms, and vestibular mechanisms (for discussion see Devinsky et al. [13] and Brugger et al. [5]). More recently, Blanke et al. [8••] suggested a differential implication of vestibular processing in the different forms of AP. These authors suggested systematic differences in the strength of a vestibular dysfunction in AH, HAS, and OBE. The role of the vestibular system for AP al so is supported by descriptions of vestibular sensations during AP in healthy populations $[15,16,21]$. Blanke et al. [8・•] suggested that OBEs were associated with a gravitational, otolithic, vestibular disturbance, whereas the vestibular dysfunction in patients with HAS is more variable and often is characterized by rotational components. Vestibular dysfunction was absent in patients with AS. Based on this neurologic evidence, these authors suggested that AP may relate to dysfunctional multisensory integration at the TPJ [8・•]. Additional vestibular dysfunctions may be irrel evant for $\mathrm{AH}$, but are increasingly important in HAS and OBE. Although these propositions seem promising, the rarity of AP in clinical and healthy populations renders their experimental investigation difficult.

There are several studies that provided theoretical propositions for experimental studies with respect to AP $[14 \bullet \bullet, 15,22,23]$. Concretely, these studies suggested that brain mechanisms engaged during mental own-body transformations may rely on similar brain mechanisms to those underlying AP. We recently did a series of experimental studies to test some of these propositions [9•]. In an evoked potential mapping study, we showed the selective activation of the TPJ at 330 to 400 ms after stimulus onset when heal thy volunteers imagined themselves in the position and visual perspective general ly reported by people experiencing spontaneous OBEs. In an independent study sample, we showed that interference with the TPJ by transcranial magnetic stimulation at that time impaired the mental transformation of the own body in heal thy volunteers rel ative to transcranial magnetic stimulation over a control site at the intraparietal sulcus. No such inference was observed for imagined spatial transformations of external objects, suggesting the sel ective implication of the TPJ in mental imagery of one's own body. Lastly, in an epileptic patient with OBEs originating from the TPJ, we showed partial activation of the seizure focus during mental transformations of her body and visual perspective mimicking her OBE percept. These results suggested that the TPJ is a crucial structure for the conscious experience of the normal self mediating spatial unity of self and body.

Taken together, the aforementioned clinical and experimental findings suggest that deficient multisensory integration (involving visual, somatosensory, and vestibular processing) and mental own body imagery (involving visuo-spatial perspective taking, self-location, and spatial unity) seem crucial for our understanding of deviant selfprocessing as occurs during AP. In addition, the use of mental own-body transformation using paradigms implicating imagery perspective changes and imagery selflocation may allow linkage of lower level multisensory processing with higher level processing in regard to body, self, and AP.

Yet, given that AP occur spontaneously and rarely in normal, neurologic, and psychiatric populations and rarely in neurologic patients, we propose that it may be favorable to additional ly screen and investigate individuals from heal thy and psychiatric populations who may have an enhanced risk and/or chance to experience an AP. This is additional ly devel oped in the remainder of this article. First, based on the illusory character of AP and the link between epilepsy and psychiatry [24,25], we discuss scientific evidence regarding psychotic populations as a potentially "AP-prone" population. We also discuss other AP-prone populations (individuals with depression, anxiety, depersonalization, and body dysmorphic disorders), who may be likely candidates for AP because of previously reported multisensory integration deficits and vestibular dysfunctions (We refer mainly to recent studies for two reasons. First, these studies use current diagnostic criteria [D iagnostic and Statistical $M$ anual of $M$ ental $D$ isorders, International Classification of Diseases of the World $\mathrm{H}$ ealth O rganization]. Second, an extensive historical overview is beyond the scope of this article. The reader can obtain more information in the cited articles). We also discuss the potential implication of the TPJ in these syndromes. 


\section{Psychiatry \\ Psychosis}

Aberrant bodily experiences have been described as core features in schizophrenia [26,27] (see [28-30] for recent overviews). Schneider [31] described del usional perceptions and somatic and passivity experiences as first-rank symptoms of schizophrenia; they also have been referred to as a loss of "Meinhaftigkeit" (mineness). Recent descriptions of body-image aberrations in patients with schizophrenia include perceptions of alterations in the size and shape of the own body, feelings of bodily unreality, merging of the body with external objects, and of the own body as not belonging to oneself [28]. Röhricht and Priebe [30] described enhanced body sensations of numbness and/or stiffness, desomatization, abnormal pain, emptiness, heaviness, lightness, falling and/or sinking, levitation and/or elevation, diminution, shrinking, enlargements, or constrictions (see also [27]). A major part of these symptoms al so have been described by neurologic patients with AP $[5,8 \cdot \bullet]$.

Angyal [27] presented a patient with schizophrenia perceiving an "alter ego" (or Doppel gänger). APs have been considered visual pseudohallucinations $[8 \bullet \bullet, 14 \bullet \bullet]$ and may be conceptualized as just another positive symptom in psychosis [32•]. However, Blackmore [33] and Röhricht and Priebe [29] found no evidence for a higher prevalence of OBEs in patients with schizophrenia when compared with healthy control subjects.

A recent study reporting somatic delusions in psychosis included AP as a distinct category [32•]. Theauthors assessed somatic delusions in many patients with depression, mania, chronic schizophrenia, and acute schizophrenia, respectively. The finding most relevant to this article is the observation that only acute psychotic patients reported loss of boundary (3.2\% of psychotic patients; eg. "other bodies intermingled with mine") and AP ( $2 \%$ of psychotic patients; "standing outside myself looking at myself" [OBE], or "can see inside myself from a height "[OBE-like]). These findings from McGilchrist and Cutting [32•] may point to a link between AP and schizophrenia, but only when patients have acute psychotic symptoms.

Further support for a link between positive psychotic symptoms and AP has been provided from heal thy schizotypal individuals $[34,35]$. These authors observed that heal thy individuals, who have experienced an OBE at least once in their lifetime, also reported higher positive, but not negative, schizotypal thoughts. Moreover, those who experienced OBEs also were those who were more prone to experience other positive "psychotic-like" experiences, such as hallucinations and involuntary imagery in situations of mild sensory limitation and physical relaxation compared with subjects who never experienced an OBE [34]. The relationship between OBEs and positive "psychotic-like" experiences is additionally supported by studies that have shown that people with OBEs al so had elevated paranormal belief scores [36] and reported hallucination-like experiences more frequently [37•••] (additional information linking OBE with personal ity, behavior, or drug use can befound elsewhere [38,39]).

Based on the previously described neurologic data, we also expected to find multisensory and vestibular deficits specifical ly related to positive psychotic or schizotypal symptoms and/or to the TPJ. Unfortunately, reports on multisensory integration in schizophrenia (see [40] for review), particularly multisensory integration of bodily information, are relatively sparse (see [41,42] for reviews). In the study by Spence et al. [41], patients showing passivity symptoms (such as loss of agency and/or al ien control) were asked to move a joystick with the right hand to the sound of auditory stimuli. Compared with normal control subjects and patients without passivity symptoms, this patient population showed a hyperactivation of right inferior parietal lobule and cingulate gyrus. Farrer et al. [42] tested action attribution in patients with Schneiderian first-rank symptoms. The task required self-other decisions about seen hand movements on a computer screen. Crucially, the spatial match between own hand position and the one seen on the screen was distorted gradually. Supporting previous reports that the right inferior parietal lobule is involved in the attribution of action to another agent [43], increased brain activity in the right angular gyrus was observed in the normal participants with increased deviance of seen hand positions from their own hand positions. In first-rank patients, this relationship was absent or much weaker and correlated positively with firstrank symptoms. The authors also reported that the lack of increase in activation caused by increasing degrees of distortion among in these patients was associated with an abnormally high level of activation in the perfectly matching condition (an increased activity that only appeared for the "other" condition). Therefore, the patients showed high activity in the right angular gyrus when they experienced being the agent of their actions, whereas this activation in normal control subjects is only seen when agency is allocated to another person.

Even less is known about vestibular dysfunction in schizophrenia. Early reports described a reduced reactivity of the vestibular system in (mainly catatonic) patients with chronic schizophrenia [44]. However, a subsequent review disqualified vestibular dysfunctions of peripheral or central origins in schizophrenia [45]. However, as argued for a relationship between psychosis and AP, vestibular dysfunctions may only be relevant when patients show acute symptoms [46]. To our knowledge, there are no research findings applying contemporary methodologies to study the vestibular system in positive psychotic patients.

The lack of consistent reports of AP in schizophrenia may be explained as follows. First, AP have not yet been related systematically to positive symptoms in schizophrenia because studies rarely distinguished between acute and chronic symptoms and medication. Second, the lack of reports of AP in psychosis may be the result of the fact that 
clinicians do not ask their patients about these not wellknown experiences (see [47] for a similar argument on ol factory hallucinations). Lastly, for patients with active psychotic symptoms, AP experiences may be just another odd experience that they do not consider worth mentioning.

\section{Depression, anxiety, depersonalization, and body dysmorphic disorders}

As will beshown in more detail below, depression, anxiety, depersonalization, and body dysmorphic disorders are frequent comorbidities [48-50]. Moreover, they also have been linked to (acute) psychosis and aberrant body experiences. Therefore, within the scope of the current report, it seems appropriate to treat them together. Our goal is to elucidate whether these syndromes may represent "APprone" subpopulations and whether multisensory and vestibular processing deficits and an implication of the TPJ have been described.

A link between AP and the latter syndromes has been hypothesized previously [17,51-54]. Chapman et al. [28] noted that patients with schizophrenia do not only have more body image aberrations as compared to normal control subjects, but that body image aberrations increased as a function of individuals' scores on the Beck's depression inventory. Dening and Berrios [17] reviewed patients with $\mathrm{AH}$ and HAS and found that more than $50 \%$ of patients studied suffered from depression followed by schizophrenia. Anxiety was comorbid in approximately $30 \%$ of patients with depression. Although information about depersonal ization was not available for many patients, $27 \%$ of the AP patients for whom this information was provided received the additional diagnosis of depersonalization.

Aberrant body experiences are phenomenologically reminiscent of AP and are common in patients with depersonalization and body dysmorphic disorders. Murray and Foxe [55] have shown that heal thy subjects with OBEs score higher on the somatoform dissociation scale and the body satisfaction scale. Depersonal ization and body dysmorphic disorders were formerly classified as anxiety disorders, whereas today, depersonalization is classified as a dissociative disorder and body dysmorphic disorders are classified as somatoform disorders [56]. Criteria of depersonalization include persistent or recurrent experiences of feeling detached from one's mental processes or body [56]. Criteria for body dysmorphic disorders include obsession about the size and shape of different body parts [56]. Although they are considered to be distinct syndromes, both are closely related with anxiety and depression [30,50,57]. Röhricht et al. [30], for instance, reported a significantly increased amount of body dissatisfaction, high amount of somatic complaints, somatic depersonalization, and boundary loss in patients with depression and anxiety as compared with normal control subjects. In a study testing a large population of patients with depersonalization disorders, Axis I comorbidity of anxiety and depression were the most prevalent [58].

With respect to multisensory and vestibular deficits in these syndromes, multisensory integration deficits have been reported in patients with state and trait anxiety $[59,60]$. Vestibular dysfunctions have been associated with depression, anxiety, and depersonalization [49,61,62]. Anatomically, anxiety, depression, depersonalization, and body dysmorphic disorders have been linked with the heteromodal association cortex such as the TPJ [57,63-67]. Simeon et al. [57] tested brain metabolism in eight patients with depersonalization and 24 heal thy control subjects using positron emission tomography. The most important finding was that patients showed higher metabolic rates in parietal and temporo-parietal cortices. Moreover, there was a positive correl ation between the relative glucose metabolism and the degree of dissociation and/or depersonalization. Using lesion analysis, Si erra et al. [63] observed depersonalization symptoms in a patient subsequent to a right subdural hematoma predominating in the right parietal lobe. Lastly, Osuch et al. [65] used positron emission tomography in medication-free patients with depression. Their results showed that these patients' state anxiety correlated inversely with metabolic rate at the TPJ (at the angular gyrus).

Multisensory integration deficits, vestibular dysfunctions, and an implication of the TPJ have been reported in patients with anxiety, depression, depersonalization, and body dysmorphic disorders. This phenomenologic and experimental evidence suggests that these syndromes may be promising research targets to further our understanding of the functional mechanisms (multisensory and vestibular processing) and neural mechanisms of AP at the TPJ and other brain areas. Unfortunately, the comorbidity of the syndromes (including psychosis) makes a more refined selection of AP-prone individuals almost impossible For instance, anxiety has been related to schizophrenia [26,68] schizotypy [69], depression [70], dissociation and/or depersonalization [58], and body dysmorphic disorders [71]. Furthermore, depression and depersonalization are associated with the schizophrenia spectrum $[72,73]$, especially for patients during an acute phase of their illness [74]. However, it may be suggested that anxi ety is the strongest predictor for AP given the important role of vestibular dysfunctions in anxiety [62]. Given the presumable role of anxiety as discussed previously, we suggest that anxiety is most closely linked to the form of AP that is characterized by complete disembodiment (as in OBE), al so attributable to the vestibular invol vement in anxiety and OBEs. However, AH may instead be linked to depersonalization and body dysmorphic disorders, in which multisensory bodyrelated information processing is disturbed without the significant implication of vestibular dysfunctions. 


\section{Condusions}

The current review indicates that a more detailed questioning of patients with AP by neurologists and psychiatrists is mandatory. To differentiate between the different forms of $A P$ and their respective incidence in the different syndromes, future studies need to refine the questions that are asked about AH, HAS, and OBEs. Most studies to date only used Pal mer's question ([75] question 23): "Have you ever had an experience in which you felt that "you" were located "outside of" or "away from" your physical body; that is the feeling that your consciousness, mind, or center of awareness was in a different place from your physical body?" McCreery and Claridge [37••] questioned the specificity of Palmer's question, stating that this question includes a wider range of unusual experiences different from OBEs. Therefore, to differentiate between $\mathrm{AH}, \mathrm{HAS}$, and $O B E$, future investigators should not only specify disembodiment, but also ask about autoscopy (Does the subject experience seeing her own body during the AP?) and the subject's visuo-spatial perspective during the experience (Does the subject experience seeing her own body and space from her habitual body-centered perspective or from an elevated and distanced extracorporeal perspective?). The accurate description of these three main phenomenol ogic characteristics of AP will not only allow to differentiate between the different $A P$-forms $(A H, H A S$, and $\mathrm{OBE}$ ), but also between AP and other phenomena such as depersonal ization or the feeling of a presence [76].

In science the most challenging phenomena often are theones we takefor granted in our everyday lives. Excellent examples are the self and the experienced spatial unity (between self and body). Folk and psychologic notions are challenged by AP. The reviewed evidence from neurologic and psychiatric patients experiencing these striking dissociations between self and body suggests that AP are culturally invariant phenomena that can be investigated scientifically. The neuroscientific study of the self is in its infancy and there are currently no established models, very little data, and often not even the vocabulary to describe neuroscientific notions of the self [1]. The investigation of AP in specific neurologic and psychiatric populations and their neural mechanisms may allow improvement of our neuroscientific models of self and corporeal awareness.

\section{Acknowledgments}

The authors are supported by the Leenaards Foundation and the Foundation de FamilleSandoz.
References and Recommended Reading

Papers of particular interest, published recently, have been

highlighted as:

- Of importance

-. Of major importance

1. Kircher T, David A: The Self in N euroscience and Psychiatry. Cambridge: Cambridge University Press; 2003.

2. Neisser U: The five kinds of self-knowledge. Phil Psychol 1988, 1:35-59.

3. Gallagher S: Philosophical conceptions of the self: Implications for cognitive science. Trends Cogn Sci 2000, 4:14-21.

4. Metzinger T: Being No O ne. Cambridge: MIT Press; 2003.

5. Brugger $P$, Regard M, Landis T: Illusory reduplication of one's own body: phenomenology and classification of autoscopic phenomena. Cogn N europsychiatry 1997, 2:19-38.

6. Ramachandran VS, Hirstein W: The perception of phantom limbs. Brain 1998, 121:1603-1630.

7. Halligan PW: Phantom limbs: The body in mind. Cogn N europsychiatry 2002, 7:251-268.

8. •- Blanke O, Landis T, Spinelli L, Seeck M: O ut-of-body experience and autoscopy of neurological origin. Brain 2004, 127:243-258.

This study analyzed phenomenologic, neuropsychologic, and neuroimaging correlates of six patients with autoscopic hallucination, heautoscopy, and out-of-body experiences. The authors proposed that all three autoscopic phenomena are attributable to different levels of multisensory integration failure at the temporo-parietal junction.

9. - Blanke O, Mohr C, Michel CM, et al.: Linking out-of-body experience and self pocessing to the temporo-parietal junction. J N eurosci 2005, 25:550-557.

By using a mental own-body imagery paradigm (adapted to the phenomenology of out-of-body experiences), and evoked potential mapping and transcranial magnetic stimulation, the authors describe a selective activation of the right temporo-parietal junction at 330 to $400 \mathrm{~ms}$ in healthy volunteers and a patient with out-of-body experiences of neurologic origin.

10. Hécaen $\mathrm{H}$, Ajuriaguerra J: L'heautoscopie. In M econnaissances et hallucinations corporelles. Edited by Hécaen $\mathrm{H}$, Ajuriaguerra J. Paris: Masson; 1952:310-343.

11. Blanke O: Illusions visuelles. In N euro-ophtalmologie. Edited by Safran AB, Vighetto A, Landis T, Cabanis E. Paris: Masson; 2004:147-150.

12. Brugger P: From phantom limb to phantom body. In Perception of the H uman Body Inside O ut. Edited by Knoblich G, Thomton I, Grosjean M, Shiffrar M. Oxford: Oxford University Press; In press

13. Devinsky O, Feldmann E, Burrowes K, Bromfeld E: Autoscopic phenomena with seizures. Arch $N$ eurol 1989, 46:1080-1088.

14. • Brugger P: Reflective mirrors: perspective taking in autoscopic phenomena. Cogn N europsychiatry 2002, 7:179-194.

The author analyzed the phenomenology of AP and proposed a systematic classification for autoscopic hallucination, heautoscopy, and out-of-body experience by relying on cognitive, psychologic, and neurologic findings.

15. Blackmore S): Beyond the Body. An Investigation of O ut-of-Body Experiences. London: Heinemann; 1982.

16. Irwin HJ: Flight of $\mathrm{M}$ ind: a Psychological Study of the $\mathrm{O}$ ut-of-Body Experience. Metuchen, NJ: The Scarecrow Press, Inc; 1985.

17. Dening TR, Berrios GE: Autoscopic phenomena. Br J Psychiatry 1994, 165:808-817.

18. Blanke O, Arzy S: The out-of body experience. Disturbed self processing at the temporo-parietal junction. $N$ euroscientist 2005, 11:16-24. 
19. Blanke O, Ortigue S, Landis T, Seeck M: Stimulating illusory own-body perceptions. N ature 2002, 419:269-270.

20. Maillard L, Vignal JP, Anxionnat R, et al.: Semiologic value of ictal autoscopy. Epilepsia 2004,

45:391-394.

21. Green CE: 0 ut-of-Body Experiences. London: Hamish Hamilton; 1968.

22. Cook AM, Irwin HJ: Visuospatial skills and the out-of-body experience. J Parapsychol 1983, 47:23-35.

23. Amorim MA: "What is my avatar seeing?": The coordination of "out-of-body" and "embodied" perspectives for scene recognition across views. Vis Cogn 2003, 10, 157-199.

24. Taylor DC: Factors influencing the occurrence of schizophrenialike psychosis in patients with temporal lobe epilepsy. Psychol M ed 1975, 5:249-254.

25. Taylor DC: Schizophrenias and epilepsies. Why? When? How? Epilepsy Behav 2003, 4:474-482.

26. Bleuler E: D ementia Praecox or the Group of the Schizophrenias. New York: International University Press; 1950.

27. Angyal A: The experience of the body-self in schizophrenia. Arch of N eurol Psychiatr 1936, 35:1029-1053.

28. Chapman LJ, Chapman JP, Raulin ML: Body-image aberration in Schizophrenia. J Abnorm Psychol 1978, 87:399-407.

29. Röhricht F, Priebe S: Disturbances of body experience in schizophrenic patients. Fortschr N eurol Psychiatr 1997, 65:323-336.

30. Röhricht F, Priebe S: Do cenesthesias and body image aberration characterize a subgroup in schizophrenia?. Acta Psychiatrica Scan 202, 105:276-282.

31. Schneider K: Clinical Psychopathology (translated by MW Hamilton). New York: Grune \& Stratton; 1959.

32. McGilchrist I, Cutting J: Somatic delusions in schizophrenia and the affective psychoses. Br J Psychiatry 1995, 167:350-361.

This report analyzed the somatic delusions and illusions (induding autoscopic phenomena) reported by 550 psychotic patients (depression, mania, schizophrenia) systematically collected over 17 years.

33. Blackmore SJ: O ut-of-body experiences in schizophrenia. A questionaire survey. J N erv M ent Disease 1986, 174:615-619.

34. McCreery C, Claridge G: A study of halluciantation in normal subjects: II. Electrophysiological data. Pers Ind D ifferences 1996, 21:749-758.

35. McCreery C, Claridge G: Healthy schizotypy: the case of outof-the-body experiences. Pers I nd D ifferences 2002, 32:141-154.

36. Tobacyk JJ, Mitchell TP: The out-of-body experience and personality adjustment. J N erv M ent D is 1987, 175:367-370.

37. $\bullet$ McCreery C, Claridge G: O ut-of-the body experiences and personality. I Soc Psych Res 1995, 60:129-148.

This study provided a broad overview regarding a presumable link between out-of-body experiences and several personality and psychiatric variables.

38. Ohayon MM: Prevalence of hallucinations and their pathological associations in the general population. Psychiatry Res 2000, 97:153-164.

39. Buenning S, BlankeO: The out-of-body experience. Precipitating factors and neural correlates. Prog Brain Res. In press.

40. de Gelder B, Vroomen J, de Jong SJ, et al.: Multisensory integration of emotional faces and voices in schizophrenics. Schizophr Res 2005, 72:195-203.

41. SpenceSA, Brooks DJ, Hirsch SR, et al.: A PET study of voluntary movement in schizophrenic patients experiencing passivity phenomena (delusions of alien control). Brain 1997, 120:1997-2011.

42. Farrer $C$, Franck N, Frith $C D$, et al.: Neural correlates of action attribution in schizophrenia. Psychiatry Res 2004, 131:31-44.

43. Ruby $P$, Decety J: Effect of subjective perspective taking during simulation of action. PET investigation of agency. $N$ at $N$ eurosci 2001, 4:546-550.

44. Angyal A, Sherman MA (1941/42). Postural reactions to vestibular stimulation in schizophrenic and normal subjects. Am J Psychiatry 98, 857-862.
45. Levy DL, Holzman PS, Proctor LR: Vestibular dysfunction and psychopathology. Schizophr Bull 1983, 9:383-438.

46. Jones AM, Pivik RT: Abnormal visual--vestibular interactions in psychosis. Biol Psychiatry 1983, 18:45-61.

47. Rubert SL, Hollender MH, Mehrhof EG: Olfactory hallucinations. Arch Gen Psychiatry 1975, 5:313-318.

48. Grunfeld EA, Gresty MA, Bronstein AM, Jahanshahi M: Screening for depression among neuro-otology patients with and without identifiable vestibular lesions. Int J Audiol 2003, 42:161-165.

49. Eckhardt-Henn A, Breuer P, Thomal ske C, et al.: Anxiety disorders and other psychiatric subgroups in patients complaining of dizziness. J Anxiety Disord 2003, 17:369-388.

50. Phillips KA, Siniscalchi JM, McElroy SL: Depression, anxiety, anger, and somatic symptoms in patients with body dysmorphic disorder. Psychiatr Q, 2004, 75:309-320.

51. Mellor CS: Depersonalization and self perception. $\mathrm{Br}$ J Psychiatry 1988, 153(Suppl. 2):15-19.

52. Lukianowic N: Autoscopic phenomena. Arch N eurol Psychiatr 1958, 80:199-220.

53. Menninger-Lerchenthal E: D as Truggebilde der eigenen Gestalt (H eautoskopie, D oppelgänger). Berlin: Karger; 1935.

54. Ohayon MM: Prevalence of hallucinations and their pathological associations in the general population. Psychiatry Res 2000, 97:153-164.

55. Murray C, Foxe J: The out-of-body experience and body image: Differences between experients and nonexperients. J N erv M ent D is 2005, 193:70-72.

56. American Psychiatric Association: D iagnostic and Statistical $M$ anual of M ental Disorders (Text Revision), Fourth Edition. Washington, DC: American Psychiatric Association, 2000.

57. Simeon $D$, Gural nik $O$, Hazlett EA, et al.: Feeling unreal: a PET study of depersonalization disorder. Am J Psychiatry 2000, 157:1782-1788.

58. Simeon D: Depersonalisation disorder: a contemporary overview. CN S D rugs 2004, 18:343-354.

59. Jacob RG, Furman JM, Durrant JD, Turner SM: Panic, agoraphobia, and vestibular dysfunction. Am J Psychiatry 1996, 153:503-512.

60. Viaud-Delmon I, Berthoz A, Jouvent R: Multisensory integration for spatial orientation in trait anxiety subjects: absence of visual dependence. Eur Psychiatry 2002, 17:194-199.

61. Grigsby JP, Johnston CL: D epersonalization, vertigo and Meniere's disease. Psychol Rep 1989, 64:527-534.

62. Asmundson GJ, Larsen DK, Stein MB: Panic disorder and vestibular disturbance: an overview of empirical findings and clinical implications. J Psychosom Res 1998, 44:107-120.

63. Sierra M, Lopera F, Lambert MV, et al.: Separating depersonalisation and derealisation: the relevance of the "lesion method". J N eurol N eurosurg Psychiatry 2002, 72:530-532.

64. Bench CJ, Friston KJ, Brown RG, et al.: Regional cerebral blood flow in depression measured by positron emission tomography: the relationship with clinical dimensions. Psychol $M$ ed 1993, 23:579-590.

65. Osuch EA, Ketter TA, Kimbrell TA, et al.: Regional cerebral metabolism associated with anxiety symptoms in affective disorder patients. Biol Psychiatry 2000, 48:1020-1023.

66. Gardner A, Pagani $M$, Jacobsson $H$, et al.: D ifferences in resting state regional cerebral blood flow assessed with 99mTc-H MPAO SPECT and brain atlas matching between depressed patients with and without tinnitus. N ucl M ed Commun 2002, 23:429-439.

67. Yaryura-TobiasJA, Neziroglu F, Torres-Gallegos M: Neuroanatomical correlates and somatosensorial disturbances in body dysmorphic disorder. CN S Spectr 2002, 7:432-434.

68. Braga RJ, Petrides G, Figueira I: Anxiety disorders in schizophrenia. Compr Psychiatry 2004, 45:460-468.

69. Braunstein-Bercovitz $\mathrm{H}$ : Is the attentional dysfunction in schizotypy related to anxiety? Schizophr Res 2000, 46:255-267.

70. Belzer K, Schneier FR: Comorbidity of anxiety and depressive disorders: issues in conceptualization, assessment, and treatment. J Psychiatr Pract 2004, 10:296-306. 
71. BohneA, Keuthen NJ, Wilhelm S, et al.: Prevalence of symptoms of body dysmorphic disorder and its correlates: a crosscultural comparison. Psychosomatics 2002, 43:486-490.

72. Kulhara P, Avasthi A, Chadda R, et al.: Negative and depressive symptoms in schizophrenia. Br J Psychiatry 1989, 154:207-211.

73. Pope CA, Kwapil TR: Dissociative experiences in hypothetically psychosis-prone college students. J N erv M ent D is 2000, 188:530-536.
74. Koreen AR, Siris SG, Chakos M, et al.: Depression in firstepisode schizophrenia. Am J Psychiatry 1993, 150:1643-1648.

75. Palmer J: A community mail survey of psychic experiences. J Am Soc Psych Res 1979, 73:221-251.

76. Brugger $P$, Regard $M$, Landis T: Unilaterally felt presences: The neuropsychiatry of one's invisible doppelgänger. N europsychiatr N europsychol Behav N eurol 1996, 9:114-122. 